\title{
Phenotypic resistance diversity underpinned by a diverse repertoire of candidate NLR loci and genotype-specific expression patterns
}

\author{
Pezhman Safdari ${ }^{1}$, Layla Höckerstedt ${ }^{1}$, Mikael Brosche ${ }^{1}$, Jarkko Salojärvi² ${ }^{2}$, and Anna-Liisa \\ Laine $^{1}$ \\ ${ }^{1}$ University of Helsinki \\ ${ }^{2}$ Nanyang Technological University
}

May 5, 2020

\begin{abstract}
High levels of phenotypic variation in resistance appears to be nearly ubiquitous across natural host populations. To date, the molecular processes associated with this variation in nature are poorly known, although theory predicts resistance to evolve at specific loci in response to pathogen -imposed selection. Nucleotide-binding leucine-rich repeat (NLR) genes play an important role in pathogen recognition, downstream defense responses and defense signaling. Exploring the depth of NLR natural variation has the potential to increase our understanding of how NLR diversity is generated and maintained, and how to manage disease resistance. Here, we sequenced the transcriptomes of five different Plantago lanceolata genotypes in response to inoculation by the same strain of obligate fungal pathogen Podosphaera plantaginis. A de novo transcriptome assembly of RNA-sequencing data yielded 24332 gene models with N50 value of 1329 base pairs and gene space completeness of 66.5\%, suggesting a highquality assembly. The gene expression data showed highly varying responses, with each plant genotype having a unique gene expression profile in response to the pathogen, regardless of the resulting resistance phenotype. We discovered a diverse NLR repertoire in P. lanceolata which is consistent with high phenotypic resistance diversity and high genetic diversity of the species. We find evidence of selection generating diversity at some of the NLR loci. Jointly, our results demonstrate that phenotypic resistance diversity results from a crosstalk between different defense mechanisms. In conclusion, characterizing the architecture of resistance in natural host populations may shed unprecedented light on the potential of evolution to generate variation.
\end{abstract}

\section{Key words:}

Phenotypic variation, pathogen imposed selection, phenotypic resistance diversity, gene expression profile

\section{INTRODUCTION}

Pathogens and herbivores play an important role in maintaining biodiversity in natural populations (Bever, Mangan, \& Alexander, 2015; Kursar et al., 2009). The threats imposed by pathogens on humans and on managed, food production systems have motivated research that aims to predict where pathogens will occur and how risks of infection evolve (Gilligan, 2002; Koff, 1992; Woolhouse, Taylor, \& Haydon, 2001). Pathogens can only occur where they have susceptible hosts, and hence, resistance diversity is the key determinant of disease dynamics. Thus, our ability to understand how diversity in resistance is generated and maintained underlies our ability to predict and prevent disease emergence and epidemics. In agriculture increasing the diversity of crops - even from a monoculture to a mixture of two cultivars - has been shown to reduce disease levels significantly (Mundt, 2002b; Zhu et al., 2000). Natural host populations typically support diversity 
in resistance phenotypes (Laine, Burdon, Dodds, \& Thrall, 2011; Salvaudon, Giraud, \& Shykoff, 2008), and limited data available to date show that increasing resistance diversity decreases disease risk also in the wild (Jousimo et al., 2014a).

Hosts and pathogens are assumed to coevolve through Red Queen dynamics, where the pathogen overcomes host's defenses and the host in turn responds with new counter-defenses (Hamilton, 1980; Jaenike, 1978). Theory predicts such reciprocal coevolutionary selection to be a powerful mechanism for maintaining diversity in both host and parasite populations, as the selection rate for resistance depends on the frequency of parasite alleles, and vice versa, in a negative indirect frequency-dependent manner (Bergelson, Kreitman, Stahl, \& Tian, 2001; Leonard, 1977). There are numerous examples of pathogens overcoming host resistance mechanisms, both from agriculture and from the wild (Mundt, 2002a, 2014). While evidence of resistance evolving under pathogen attack in the wild is scarce (Laine, 2006), there is ample support for coevolution from local adaptation studies where parasite/host fitness is measured in sympatry vs. allopatry (Greischar \& Koskella, 2007; Hoeksema \& Forde, 2008). To date, a handful of ground-breaking studies have demonstrated that fluctuations in resistance and infectivity in natural systems match the predictions of coevolutionary selection (Decaestecker et al., 2007; Gómez \& Buckling, 2011; Thrall et al., 2012).

The interaction between plants and their pathogens is mediated by complex defense mechanisms, incorporated in several layers of defense. Thick and waxy cell walls are an example of a mechanical defense barrier against pathogen invasion (Miedes, Vanholme, Boerjan, \& Molina, 2014). Upon the arrival of a pathogen, the pathogen-associated molecular patterns (PAMPs) trigger the so-called PAMP-triggered immunity (PTI) response, which can stop the pathogen infection even before it begins. If the pathogen succeeds in overcoming these first two defense layers, the next layer is effector triggered immunity (ETI), involving the recognition of pathogen virulent factors (effector proteins), either directly or indirectly by recognizing the modifications that they make to the plant proteins (Jones \& Dangl, 2006). Many of the proteins involved in intracellular pathogen recognition belong to nucleotide-binding-leucine-rich repeat (NLR) receptors (Monteiro \& Nishimura, 2018). After pathogen recognition a multitude of different signaling pathways, including production of reactive oxygen species, elevated $\mathrm{Ca}^{2+}$ and MAP kinases lead to activation of plant defenses. These defenses include the induction of stress hormones salicylic acid, jasmonic acid and ethylene, as well as extensive transcriptional re-programming ultimately resulting in the production of defensive compounds, such as toxic secondary metabolites and antimicrobial chemicals and enzymes. Against some pathogens, plants also activate the hyper-sensitive response, programmed cell death, in which the plant rapidly kills the cells surrounding the infection to prevent the spread to nearby tissues (Coll, Epple, \& Dangl, 2011; Egorov \& Odintsova, 2012).

Within these defense responses, NLR proteins play a key role. They are involved in recognition of the pathogen's effector proteins both directly and indirectly, as well as in triggering the plant immune response (Meunier \& Broz, 2017). NLRs have also been shown to be involved in signaling and transcript regulation (Chisholm, Coaker, Day, \& Staskawicz, 2006; Jones \& Dangl, 2006). Moreover, NLR genes play an important role in local adaptation and habitat expansion of plants (Stam et al., 2017; Thrall et al., 2012). The antagonistic interaction between plant NLR and pathogen effector proteins is considered to have a profound effect on the evolution of both organisms, shaping their genomes and gene repertoire (Upson, Zess, Bialas, Wu, \& Kamoun, 2018). NLRs usually form large tandemly arrayed gene families and hence questions regarding their origins and evolutionary history have been under active research in both plants and animals (Andolfo et al., 2019; Borrelli et al., 2018). The numbers of identified NLRs differ substantially within and between plant families (Baggs, Dagdas, \& Krasileva, 2017), for example Arabidopsis thaliana (Arabidopsis) contains between 165 to 251 NLR genes (Shao et al., 2016; Van de Weyer et al., 2019) and crop species such as wheat, barley, rice, tomato and potato contain 627, 224, 438,137 and 309 NLRs, respectively (Sarris, Cevik, Dagdas, Jones, \& Krasileva, 2016). In A. thaliana there is evidence of widespread positive selection in the core NLRs shared among accessions, especially in the canonical NLR domains (Van de Weyer et al., 2019), while a pioneering study on wild tomato revealed high NLR diversity with a small subset of NLR genes driving local adaptation to pathogens (Stam et al., 2017). 
A current key challenge in molecular ecology is to understand the role of pathogen-imposed selection on generating NLR diversity. Exploring the breadth and depth of plant NLR natural variation has the potential to increase our understanding of how NLR diversity is generated and maintained, and to establish a toolbox of deployable disease resistance traits (Monteiro \& Nishimura, 2018). In natural plant populations, neither pathogen epidemiology nor host resistance is under human management in contrast to agricultural systems where disease is managed both via resistance breeding and fungicides. Hence, natural populations have the potential to offer unique insight into the processes generating NLR diversity. Our study is focused on the interaction betweenPlantago lanceolata and its fungal pathogen Podosphaera plantaginis . Previous studies have detected considerable phenotypic variation in $P$. lanceolata resistance against $P$. plantaginis (Laine, 2004); diversity is shown to accumulate in the well-connected populations across the landscape (Hockerstedt, Siren, \& Laine, 2018), and has a direct negative impact on disease dynamics (Jousimo et al., 2014b). Moreover, there is evidence of coevolution in this interaction (Laine, 2005, 2006, 2008).

Here, we carried out a controlled experiment where five $P$. lanceolata individuals were inoculated with the same $P$. plantaginis strain. The aim of our study was to characterize the transcriptional responses and the expression pathways activated in response to the pathogen treatment, as well as in resistant versus susceptible phenotypes. For this purpose, we carried out the firstde novo transcriptome assembly for P. lanceolata and used it to characterize the induced NLR repertoire in $P$. lanceolataand test whether any particular NLRs show signs of selection. We found that each plant genotype demonstrated a unique gene expression profile in response to the pathogen and discovered a diverse NLR repertoire in P. lanceolata which is consistent with the high phenotypic resistance diversity uncovered in earlier studies.

\title{
MATERIALS AND METHODS
}

\author{
Study system and plant and fungal material
}

Ribwort plantain, Plantago lanceola L., is a perennial monoecious plant that reproduces both sexually by wind pollination, and clonally by producing side rosettes (Sagar \& Harper, 1964). Podosphaerea plantaginis (Castagne; U. Braun and S. Takamatsu) (Erysiphales, Ascomycota) is a specialist obligate biotroph infecting P. lanceolata. As all powdery mildews, it requires living host tissue throughout its life cycle (Bushnell, 2002), and completes its life cycle as localized lesions on host leaves. Infected plants suffer significant stress, and infection may increase host mortality (Laine, 2004). The interaction between P. lanceolata and P. plantaginis is strain-specific suggesting gene-for-gene type control (Laine, 2004, 2007; Thompson \& Burdon, 1992). In some cases the host can mitigate pathogen's reproduction; the putative resistance mechanism includes two steps, where the host plant first recognizes the attacking pathogen and blocks its growth (Laine, 2004) and the following infection outcome depends on both host and pathogen genotypes (Laine, 2004, 2007).

In resistant interactions no infection develops, while in susceptible interactions there is considerable variation in pathogen development that is affected by both host and pathogen genotype (Laine, 2007). An inoculation protocol where conidia from small colonies or individual chains are placed on detached leaves or intact leaves of plants yields a robust characterization of resistance-susceptibility. A plant genotype is characterized as resistant when no pathogen growth is detected following inoculation, or when the test plant shows rapid cell death around inoculum source. A genotype is characterized as susceptible when infection is detected following inoculation. From an earlier large inoculation study consisting of 2944 host genotype-pathogen genotype combinations (Hockerstedt et al., 2018), we selected three genotypes (IDs 193_2, 2818_3 and 2818_6, named Res1, Res2 and Res3 here after) that were resistant against all tested pathogen strains, and two genotypes (IDs 313_6, 1553_5, named Sus1 and Sus2 here after) that were susceptible against all tested pathogen strains. Selected genotypes were cloned into six plants each as described in Laine (2004). 


\section{Inoculation experiment}

A schematic overview of the experiment design is shown in Figure 1a. When plant clones were two months old, three replicates of each of the five genotypes, in total 15 plants, were exposed to single P. plantaginis strain (Lammi_3) by brushing spores gently with a fine paintbrush onto six test leaves and two positive control leaves. Similarly, three replicates of each genotype, in total 15 plants, were mock inoculated by brushing leaves without mildew spores. Both powdery mildew and mock-inoculated leaves were marked with a piece of masking tape. Inoculated and mock-inoculated plant clones were placed in two separate growth chambers (Panasonic MLR-352) at $20 \pm 2{ }^{\circ} \mathrm{C}$ (day) and $16 \pm 2{ }^{\circ} \mathrm{C}$ (night) with 16:8 light-darkness (L:D) photoperiod, and were randomly organized to minimize potential variation in microclimatic conditions. We collected two inoculated or mock-inoculated leaves from every plant at 24,48 and 72 hours post inoculation (hpi), snap froze the leaves in liquid nitrogen, and stored samples in glassine bags in $-80{ }^{\circ} \mathrm{C}$ until RNA was extracted. Control leaves in whole plants were screened until 14 days post inoculation to detect putative powdery mildew infection to confirm the phenotypic response of the plants, resistant or susceptible. Viability of spores used in the experiment was confirmed by inoculating detached leaves of a susceptible genotype.

\section{RNA extraction}

For total RNA extraction, $0.2 \mathrm{~g}$ of frozen leaf material was ground in lysing buffer $(2 \%$ CTAB, $2 \%$ PVP K-30, $100 \mathrm{mM}$ Tris- $\mathrm{HCl} \mathrm{pH}$ 8.0, $2 \mathrm{M} \mathrm{NaCl}, 25 \mathrm{mM}$ EDTA, $\beta-\mathrm{MeOH}(200 \mu \mathrm{l} / 10 \mathrm{ml})$ added in prior to use (Chang, Puryear, \& Cairney, 1993). Thoroughly vortexed solution was then extracted twice with equal volume of acid phenol-chloroform-isoamyl-OH (ph 4.5). Prior to precipitation, $160 \mu$ l of $10 \mathrm{M} \mathrm{LiCl}$ was added and samples were kept on ice overnight, followed by 30 min centrifugation $(10000 \mathrm{rpm})$ in $+4{ }^{\circ} \mathrm{C}$. Pellets were dissolved in $500 \mu \mathrm{l}$ of $65{ }^{\circ} \mathrm{C}$ SSTE (1M NaCl, 0.5\% SDS, 10 mmTris-HCl pH 8.0, 1mM EDTA) and RNA was extracted twice with chloroform-Isoamyl alcohol (24:1). After EtOH precipitation and 70\% wash, the pellets were dissolved in $40 \mu \mathrm{H}_{2} \mathrm{O}$ and RNA quantity and quality were checked using NanoDrop (Thermo Fischer Scientific). Potential contamination of genomic DNA in the RNA samples was removed using DNase I (Thermo Fischer Scientific) and samples were then reverse-transcribed to cDNA using iScript cDNA Synthesis Kit (Bio-Rad) according to the manufacturer's instructions.

\section{Selecting the time point for RNA-Seq using Quantitative real-time PCR (qPCR)}

In order to select the most informative time point for RNA sequencing to detect significant transcriptomic responses induced by the inoculation treatment, we initially performed a gene expression analysis of selected marker genes using qPCR. We selected inoculated and mock-inoculated clones of two plant genotypes (resistant 193_2.1 and susceptible 1553_5.1), and samples from all three time points (24, 48 and 72 hours post inoculation), resulting in 12 samples. Primers were designed with Primer3 (Rozen \& Skaletsky, 1999) based on previously in situsequenced transcriptome of $P$. lanceolata (unpublished data) and known disease-induced genes in Arabidopsis. We tested seven putative disease-induced genes (Supplementary File 1). Amplification efficiencies (E) of the primer pairs were determined with five dilutions $(1: 1,1: 4,1: 24,1: 124,1: 624)$ of template cDNA, where $\mathrm{E}=10^{-1} /$ slope. The $\mathrm{qPCR}$ was performed with three technical replicates, one water control and a plate control sample in a 384-well plate with $10 \mu \mathrm{L}$ volume, using C1000 Thermal Cycler (Bio-Rad). All samples were tested for genomic DNA contamination with -RT controls prior to qPCR. Each

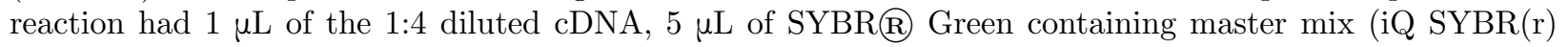
Green Supermix for qPCR; Bio-Rad), $3 \mu \mathrm{L}$ of nuclease-free water and $0.5 \mu \mathrm{L}(10 \mu \mathrm{m})$ of each primer. The cycle conditions were one cycle initiating at $95^{\circ} \mathrm{C}$ for $3 \mathrm{~min}, 40$ cycles at $95^{\circ} \mathrm{C}$ for $10 \mathrm{~s}, 60^{\circ} \mathrm{C} 30 \mathrm{~s}$, and ending with melting curve analysis. To normalize the qPCR data several different reference genes were tested and 
Elongation factor_CL4, GADPH_28221 and Actin_34737 were validated with geNorm to have stable expression in the samples used in this study (Supplementary File 1). Calculation of relative expression (CNRQ) and normalization was done in qBase+ 3.2 .

\section{RNA sequencing (RNA-Seq)}

Several studies of powdery mildew pathogen induced genes in host plants have found the highest number of differentially expressed genes in later time points (Li et al., 2016; Li, Dong, et al., 2019; Polonio et al., 2019). The $\mathrm{qPCR}$ results revealed that gene expression of the marker genes showed elevated levels in time point $72 \mathrm{~h}$ post inoculation (hpi; Supplementary Figure 1). Hence, we selected samples from time point 72 hpi for RNA sequencing. The samples were sequenced using Illumina NextSeq 500 platform in the Institute of Biotechnology of the University of Helsinki using paired end sequencing. The length of the forward reads was 78 and reverse reads 74 bases. The sequenced reads were first trimmed and low quality reads were removed using Trimmomatic software (Bolger, Lohse, \& Usadel, 2014), resulting in an average library size of 14.6 million reads.

\section{Transcriptome assembly}

We combined all libraries and assembled them de novo using Trinity software (Grabherr et al., 2011), SOAPdenovo-Trans (k-mer sizes 39, 41) (Xie et al., 2014) and Oases (k-mer sizes 39, 43 and 47) (Schulz, Zerbino, Vingron, \& Birney, 2012). Next, we combined all the resulting contigs and ran the EvidentialGene pipeline (Gilbert, 2013). We then combined okayset and okayalt outputs of the pipeline and clustered them using RapClust (Srivastava, Sarkar, Malik, \& Patro, 2016), and merged the genes within the clusters using Lace (Davidson, Hawkins, \& Oshlack, 2017). To remove contamination, the resulting contigs were aligned against NCBI non-redundant protein database (Pruitt, Tatusova, \& Maglott, 2007) using BLAST, and only the transcripts that had a best hit in plant kingdom were retained. We also removed the transcripts mapping to ribosomal genes and having ambiguous sites (Ns). Minimum read coverage of three was used for all the assemblies.

\section{Differential gene expression analysis}

All libraries (30 in total) were mapped to the combined transcriptome assembly using kallisto software (Bray, Pimentel, Melsted, \& Pachter, 2016) with one hundred bootstrap replicates. The averages of bootstrap replicates of Transcript per Million (TPM) (Li, Ruotti, Stewart, Thomson, \& Dewey, 2010) values were used as counts for differential gene expression analysis. We imported the count tables to $\mathrm{R}$ by tximport package (Soneson, Love, \& Robinson, 2015). Principal Component Analysis of all samples, both for combined and for each genotype separately was carried out using plotPCA command in DESeq2 and using rgl package (Adler, Nenadic, \& Zucchini, 2017) for 3D plot and ggplot2 (Wickham H, 2016) for 2D plots. We analyzed the samples at genotype and phenotype levels (Res, Sus and Res_vs_Sus) by DESeq2 (Love, Huber, \& Anders, 2014) to obtain differentially expressed genes.

\section{Redundancy analysis of the count data}

We used vegan package (Oksanen et al., 2018) for redundancy analysis (RDA) of the count data to identify genetic variation significantly associated with the key conditions in our experiment: Inoculation, Genotype, and Phenotype as well as the interactions of Genotype-by-Inoculation and Phenotype-by-Inoculation. The statistical significance of each of the conditions was tested with a permutation test (permtest) with 10000 
permutations. The genes contributing to significant differences along the RDA axes were identified using cut off of three standard deviations (corresponding to two-tailed p-value $=0.0027 \mathrm{in} \mathrm{Z}$ test). The overlap among gene sets was analyzed using Venn diagrams in R using venn package (Dusa, 2018).

\section{Annotation and gene ontology (GO) analysis}

To obtain a functional annotation for the transcripts, we used blastp (Camacho et al., 2009) to search for the best match among Arabidopsis representative set of proteins (Berardini et al., 2015) downloaded from TAIR FTP server (ftp://ftp.arabidopsis.org/home/tair/Proteins/TAIR10_protein_lists/). The retrieved best hit was assumed to be an Arabidopsis ortholog and the functional annotation and GO category assignment of the ortholog was transferred to the $P$. lanceolata query transcript. The Arabidopsis GO annotations were downloaded from the TAIR FTP server (ftp://ftp.arabidopsis.org/home/tair/Ontologies/Gene_Ontology/). Gene ontology enrichment analysis was carried out using piano software (Varemo, Nielsen, \& Nookaew, 2013) and the $\log _{2}$ fold changes and false discovery rate (FDR) adjusted P-values of differentially expressed genes were imported from DESeq2 results.

The GO hierarchy enrichment tests were carried out using the GOATools toolkit (Klopfenstein et al., 2018). To focus on signaling responses, we selected the responses and signaling sub-branches of the Biological process category. The GO enrichment results were plotted using $\mathrm{R}$ with fold change values obtained from the piano package. The GO enrichment analyses of RDA loadings was carried out with piano software (Varemo et al., 2013) using RDA loadings as gene level statistics and GO categories as gene set collection and mean statistics. Again, the results were plotted in R.

\section{Prediction of candidate NLRs}

To predict the candidate NLR (nucleotide binding leucine rich repeat) resistance genes in our reference transcriptome, the NLR-Parser pipeline was applied (Steuernagel, Jupe, Witek, Jones, \& Wulff, 2015). We picked the highest scoring domain found per reading frame per transcript and manually screened the ORFs containing that domain. The transcripts were left out if the ORF was too short or if they were missing the appropriate start and stop codons and BLAST queries did not identify hits from NCBI nr database. The NLR transcripts were considered to be expressed in a genotype level assembly if the count was greater than one in at least two replicates. The Venn diagram of expressed and differentially expressed NLR genes across all genotypes was made using venn package (https://CRAN.R-project.org/package=venn) in R.

Evolutionary analysis of the NLR transcripts was carried out using Antirrhinum majus L. (snapdragon) proteins and coding sequences (Li, Zhang, et al., 2019) as outgroup, since it is evolutionarily the most recently diverged plant from $P$. lanceolata where full genome assembly is available. Multiple sequence alignment of all of the NLRs in reference assembly was carried out using MAFFT, and the phylogenetic tree was estimated using FastTree (Price, Dehal, \& Arkin, 2010). ClusterPicker (Ragonnet-Cronin et al., 2013) script with 90 percent similarity and genetic distance of 0.03 with gap option was used to cut the phylogenetic tree into clusters. The longest sequence in each cluster was used as BLAST queries against snapdragon proteins and the closest hit was selected to represent the ancestral state and added to the cluster. The phylogenetic tree was first visualized using the newick format output tree produced by ClusterPicker and the final visualization was carried out with ggtree package (Yu et al., 2017) in R.

\section{Neutrality test (dN/dS and $\mathrm{H}$ statistic)}

To identify the loci under positive selection, we performed dN/dS analysis. For each cluster obtained from ClusterPicker, we used the most similar homolog in snapdragon (Antirrhimum majus L.; Li, Zhang, et al. 
(2019)) as ancestral NLR ortholog sequence for the sequences in the cluster and conducted multiple sequence alignment using MAFFT, estimated phylogenetic tree with FastTree and reverse-transcribed the alignment of the sequences. We calculated the $\mathrm{dN} / \mathrm{dS}$ ratios (ratio between non-synonymous mutations and synonymous mutations) using PAML software (Yang, 2007) within each of the clusters and used ratio $>1$ as an indicator of putative positive selection. We also calculated per base $\mathrm{dN} / \mathrm{dS}$ ratios since, due to functional constraints on conserved protein domains, it is much more likely that certain regions in a gene are under selective pressure rather than the whole gene.

We carried out the Fay \& Wu H statistic analysis (Fay \& Wu, 2000) on NLR transcripts by mapping the Plantago reads to the reference transcriptome assembly using ANGSD software (Korneliussen, Albrechtsen, \& Nielsen, 2014). To identify loci under selective pressure, we calculated the Fay \& Wu H (H) values within a sliding window of nine nucleotides. We chose $\mathrm{H}$ values less than -3.5 to signify selection. Functional domains within the transcripts were identified with InterProScan (Jones et al., 2014) search with the online InterPro service of the EMBL-EBI website (Mitchell et al., 2019). The significant $\mathrm{H}$ value loci were plotted against the transcript domain structure in $\mathrm{R}$.

\section{RESULTS}

\section{Inoculation experiment and qPCR}

We detected powdery mildew spores growing on the inoculated, susceptible plant clone leaves on day 14 post inoculation. None of the mock-inoculated or inoculated resistant plant clones showed visible disease symptoms at that time. Gene expression of the marker genes varied considerably in the susceptible inoculated plants and showed elevated levels only at time point $72 \mathrm{~h}$ post inoculation (Supplementary Figure 1). This time point was chosen for further analysis.

\section{Transcriptome assembly and expression analysis}

On average, the 90 transcriptome libraries produced around 14.6 million reads. All libraries were pooled to construct a de novo assembly with Trinity, yielding 177,948 isotigs. The assembly was of high quality, since the Busco score of universal single-copy genes (Seppey, Manni, \& Zdobnov, 2019) was 87\% (including complete and fragmented genes), but it likely contained many splice variants and allelic variants, because the proportion of duplicated gene models was high (46.3\%). Careful clustering and filtering (see M\&M) narrowed the set down to 24,332 high quality non-redundant transcripts with an average length of 1,858 bases. The procedure reduced the Busco score to $66.5 \%$, but clearly removed the allelic variants, as only $2 \%$ of gene models remained duplicated. The filtered gene models had mostly low expression counts and therefore were of low biological significance to the experiment.

On average $75 \%$ of the transcriptome data mapped to the de novoassembly (Supplementary Table 1). Principal Component Analysis (PCA) of TPM normalized gene expression data showed a clear grouping of the samples by genotype (Figure 1g) along the first three PCs. These first three PCs explained altogether 53 percent of the total variation, illustrating that genotype effect is the main contributor to the variation between samples. The inoculation treatment had a smaller but marked effect on gene expression, which was clearly demonstrated in genotype-specific PCA plots where the effect of the inoculation was associated with $\mathrm{PC} 1$ and $\mathrm{PC} 2$ axes (Figure $1 \mathrm{~b}$ to $\mathrm{f}$ ). For example, in resistant R1 and R2 genotypes the variation explained by PC1 was 65 and 52 percent, respectively, and clearly separated the inoculated and control plants (Figure $1 \mathrm{~b}$ and $\mathrm{c})$. 


\section{Differential gene expression analysis}

The PCA analyses showed marked differences between the gene expression profiles of the genotypes and their responses to the inoculation. Similarly, the genes expressed differentially between mildew inoculated and mock-inoculated plants showed high genotype-specific variation. The R1 genotype had the highest number of differentially expressed (DE) transcripts among all genotypes, 3803, from which about 2000 had absolute $\log _{2}$ fold change greater than one. On the other hand, the S2 genotype had the lowest number of DE transcripts, 43, with only 20 having absolute $\log _{2}$ fold change greater than one (Table 1; Supplementary Table 2).

\section{Redundancy Analysis (RDA)}

To study the relative effect sizes and their statistical significance, we carried out multivariate regression using Redundancy Analysis (RDA). The analysis confirmed that the genotype and phenotype (resistant versus susceptible) effects were highly statistically significant $(\mathrm{P}=0.001$ and $\mathrm{P}=0.004)$, describing $35 \%$ and $9 \%$ of the overall variation (Table 2). The effect of the inoculation treatment alone was not significant (P $=0.238$ ), but the combined effects of genotype-by-experiment and phenotype-by-experiment were significant ( $\mathrm{P}=0.001$ and $\mathrm{P}=0.048$, respectively), again suggesting genotype-specific response profiles. Accordingly, the RDA plots displayed clear separation when using genotype and phenotype as a covariate but not with inoculation treatment (Figures 2a, b and c). Venn diagrams of the genes contributing to the separation in the RDA analyses demonstrate that while 87 genes contribute significantly to separation according to genotype, only 7 genes contribute directly to the phenotypic variation and 109 genes to the joint effect of phenotype-by-experiment (Figures $2 \mathrm{~d}$ and e).

\section{Gene ontology (GO) analysis based on differential expression}

To look for common pathways that are activated by inoculation in all plants, we carried out GO enrichment analysis of the differentially expressed genes. The different responses by the genotypes were visible also at the level of activated pathways (Figure 3; Supplementary Figure 2; Supplementary Table 3). This may be due to differences in plant defense responses or manipulation of the plant defense mechanisms by the pathogen.

To explore molecular underpinnings between susceptible and resistant genotypes we searched for differential activation of defense response pathways by identifying the GOs with decreased average expression levels in susceptible phenotypes and elevated levels in resistant phenotypes. In resistant phenotypes, genes encoding photosynthesis related proteins and $\mathrm{NAD}(\mathrm{P}) \mathrm{H}$ dehydrogenase complex had increased transcript levels. This could contribute in defense against the pathogen, as it has been shown that photosynthesis plays an important role in plant defense against biotic stress (Gohre, 2015). Genes assigned to photosynthesis functions showed elevated transcript levels in susceptible phenotypes as well but not to the same extent. Chlorosis is a hallmark sign of powdery mildew infection and biotrophic fungi are known to reduce photosynthetic rate and possibly damage chloroplast structure (Perez-Bueno, Pineda, \& Baron, 2019), thus the upregulation could be either compensation, plant defense mechanism or induced by pathogen. In addition, uroporphyrinogen decarboxylase activity (GO:0004853) was upregulated in resistant phenotypes. Involved in chlorophyll biosynthesis, it also points towards acting against the chlorosis induced by the pathogen (Mock, Keetman, Kruse, Rank, \& Grimm, 1998).

Among both susceptible phenotypes, the GO category with most decreased expression levels was induction of programmed cell death (GO:0012502), suggesting that as a biotrophic pathogen, $P$. plantaginis may have disabled the programmed cell death and is keeping the host cells alive. However, also the resistant phenotypes showed reduced expression levels, possibly due to successful manipulation by the pathogen, and therefore the comparison between susceptible versus resistant did not identify this process as significantly different between phenotypes $(\mathrm{P}=0.0559)$. 
In addition to the shared responses, the genotypes showed individual enrichment of various disease resistance pathways. In susceptible genotype 1 (S1), the processes with most decreased average expression levels were tripeptide transporter activity (GO:0042937), tripeptide transport (GO:0042939) and delta12-fatty acid dehydrogenase activity (GO:0016720), whereas S2 demonstrated decrease in Oxazole or thiazole biosynthetic process (GO: 0018131) and Low-affinity nitrate transport (GO:0080054 \& GO:0080055). Fatty acids play a direct role in modulating the plant defense response to pathogens (Kachroo \& Kachroo, 2009), and thiazole or thiamine has been shown to play a crucial role in activation of the defense responses, callose/lignin deposition and stomatal closure (Zhou, Sun, \& Xing, 2013).

Tripeptide transport includes also nitrate transporters. Interestingly, powdery mildew causative agent Erysiphe necator elevates the expression levels of nitrate transporters in grapevine and Arabidopsis (Pike et al., 2014), possibly to acquire nutrients from the host. In addition to decreased levels of the GO categories related to nitrate transport in both S1 and S2, we identified homolog of Arabidopsis nitrate transporter (AtNRT1.5) to be upregulated after inoculation in susceptible vs resistant comparison. In Arabidopsis, the protein is responsible for nitrate transport from roots to shoots, and in this context suggests towards manipulation of host nutrient distribution by the pathogen. Mur, Simpson, Kumari, Gupta, and Gupta (2017) have argued that nitrogen and nitrates and their transportation to different tissues in the plant during the pathogen infection could be the "silver bullet" of the plant defense. Besides nitrate transport, tripeptide transport activities also play an important role for defense against biotic and abiotic stress (Karim et al., 2007), suggesting a reason for the decreased expression of the tripeptide transporters as a whole in the susceptible phenotypes.

In resistant phenotypes, the glucosyltransferase (GO:0050284) upregulation in R1 is a sign of early preparation for pathogen response (Le Roy, Huss, Creach, Hawkins, \& Neutelings, 2016), and in R2 genotype, the activation of NADH dehydrogenase complex assembly (GO:0010258) has been shown to be involved in defense signaling (Wallstrom et al., 2014).

\section{Gene ontology (GO) analysis based on Redundancy Analysis (RDA)}

We identified the GO categories contributing to the differences in RDA analyses by averaging the RDA loadings of the genes in each of the categories, and tested whether the values significantly differ from random scores obtained by permutation. Genes contributing to the separation between inoculation and control were enriched for $\mathrm{ABA}$ and cytokine signaling, primary metabolism and chloroplast activity. ABA induces resistance to powdery mildew in barley (Wiese, Kranz, \& Schubert, 2004), and repression of ABA biosynthesis as well as genes regulated by ABA, such as cold/dehydration/salinity responsive genes, are associated with mildew resistance in nonhost plants in general (Jensen et al., 2008). Cytokinin suppresses programmed cell death and plays a role in the synthesis and maintenance of chlorophyll (Walters \& McRoberts, 2006); both processes were enriched among the differentially expressed genes. Additionally, cytokinin levels regulate cell division together with auxin. Interestingly, in Arabidopsis, Golovinomyces orontii inoculation induced cell cycle related genes and endoreduplication, possibly due to increased metabolic demands of the pathogen (Chandran, Inada, Hather, Kleindt, \& Wildermuth, 2010). On the other hand, Choi, Choi, Lee, Ryu, and Hwang (2011) have shown that plant based cytokinins systematically induce plant resistance against pathogens by cytokinin and salicylic acid signaling.

Genes associated with the differences between the phenotypes showed GO enrichments for kinase activity, carbohydrate metabolism, plant cell wall organization, photosystem II and response to cold GO categories, whereas the genes contributing to the differences between genotypes were enriched for tryptophan metabolism, plant cell wall and chloroplast (Figure 4a and Figure 2d/e; Supplementary Figure 3). In Arabidopsis (Chandran et al., 2010), the expression of cold/drought responsive genes were decreased together with ABA biosynthesis after inoculation with $G$. orontii . Together with the observed induction of ABA 
during inoculation, this suggests that the phenotypes may differ in how strongly ABA activates its targets such as cold responsive genes.

The responses to infection start to play a role in genotype-by-experiment effect where the genes are mainly enriched for immune and defense responses, illustrating that the genes in these processes highly differ by the transcription levels between genotypes. Overall, the enriched GOs show a clear activation of defense responses in general, and defense responses to fungi in particular. The GO category with highest positive average of RDA loadings (and therefore, high contribution to separation) is aldose 1-epimerase activity (GO:0004034) which, based on Sheshukova et al. (2017), is activated because of the mechanical damage inflicted by the pathogen and results in methanol emission and priming of the non-infected leaves. The presence of hydrogen peroxide metabolic process and salicylic acid mediated signaling pathway are both well-established pathogeninduced defense mechanisms (Hua, 2009; Kuniak \& Urbanek, 2000; Niu \& Liao, 2016; Sheshukova et al., 2017), further demonstrating the activation of the defense processes due to the pathogen infection. The GO category with most negative average RDA loadings is RNA splicing, via endonucleolytic cleavage and ligation (GO:0000394). An emerging field in plant molecular biology, it is becoming increasingly clear that plants use alternative RNA splicing extensively as a means to respond to their environment and defend against pathogens (Shang, Cao, \& Ma, 2017; Staiger, Korneli, Lummer, \& Navarro, 2013). Within the signaling-specific GOs (Figure 4b) the genotype by experiment effect showed the activation of jasmonic acid (JA) and abscisic acid signaling (as expected, (Yang et al., 2019)), but again, in a genotype-specific manner. Further inspection of putative orthologs of marker genes for different hormonal signaling pathways showed activation of auxin biosynthesis and signaling, as well as differences in the activation of JA signaling and NLR signaling through EDS1 ortholog (Supplementary Table 4). In R1, specific induction of the SA biosynthesis and systemic acquired resistance was also detected.

The most significant contributor to phenotype-by-experiment is photosystem II activity. The GO category with highest average RDA loadings for phenotype by experiment effect is oligopeptide transmembrane transporter activity (GO:0035673). The perception and transduction of fungal oligopeptides will trigger multiple defense responses (Hahlbrock et al., 1995; Nurnberger et al., 1994). Multitude of photosynthetic processes were also enriched; their role in defense was discussed above. The categories with most negative average loadings were response to fungus, and cytokinin biosynthetic process (GO:0009691).

\section{NLR transcripts}

To look for the variation in the plant defense responses we carried out an in-depth study of the resistance NLR genes induced in the experiment. The transcriptome annotation predicted altogether 543 candidate NLR transcripts, and 51 of them were upregulated and 35 downregulated in resistant versus susceptible comparison. The clustering of the NLR transcripts resulted in 58 clusters containing 457 sequences and 54 singletons (Figure 5a). Cluster 69 with 22 transcripts had the highest number of transcripts. The BLAST query against Arabidopsis protein database for the longest transcript in this cluster returned a hit to the RPP13 gene. RPP13 has the highest amount of amino acid diversity in Arabidopsis and is involved in defense against Peronospora parasitica (Hall et al., 2009; Rose et al., 2004), an oomycete causing downy mildew in Brassicaceae. A closer look at the expressed NLR transcripts revealed that although many of the NLR transcripts are expressed across all genotypes, the differentially expressed NLRs differ between genotypes with no common NLR transcripts, as illustrated by Venn diagrams of all expressed and differentially expressed NLR transcripts (Figures 5b and c).

\section{Neutrality test (dN/dS and $\mathrm{H}$ statistic)}

To look for NLR clusters under positive selection, possibly in response to coevolution with the pathogen, we analysed $\mathrm{dN} / \mathrm{dS}$, the ratio between non-synonymous (amino acid changing) to synonymous mutations 
(Figure 5a, outmost ring). None of the NLR transcript clusters had an $\omega$ value greater than one, which would indicate positive selection pressure. However, site-wise analysis of $\mathrm{dN} / \mathrm{dS}$ revealed that 23 of the clusters contained a varying number of one to 12 amino acid positions under positive selection, based on Bayes Empirical Bayes (BEB) analysis ( $\mathrm{P}>95 \%$ ). The cluster with the highest number of loci under selection returned a BLAST hit to an Arabidopsis NLR protein responsible for resistance against Lettuce mosaic virus (Revers et al., 2003).

In order to investigate potential selection pressure by a complementary method, considering the shortcomings of within population dN/dS analysis (Kryazhimskiy \& Plotkin, 2008), we also calculated Fay \& Wu H statistics on the whole NLRs using putative snapdragon orthologs (Li, Zhang, et al., 2019) as the ancestral state. A positive value of $\mathrm{H}$ is an indication of balancing or purifying selection, suggesting the tendency to preserve the current protein sequence, whereas high negative values are an indication of diversifying positive selection, selective sweeps, or drift, for example from population bottlenecks.

We identified 23 NLR transcripts with regions having H statistics less than -3.5 (Figure 5a; Supplementary Figure 4; Supplementary Table 5). This set included two genes from the cluster with homology to RPP13, and the sites under selection in all but one were located in the conserved NB-ARC domain. Since this domain is the activation domain (Van Ooijen et al., 2008), the mutations may affect the strength of the activation. Additionally, we identified selection in the LRR domains of three genes. Since they are involved in pathogen perception and induced in our experiment, these domains may have been under positive selection to detect the $P$. plantaginis pathogen.

\section{DISCUSSION}

Given that pathogens are prevalent across all ecosystems, an individual's reproductive success and survival will depend on its ability to resist infection. Natural host populations have been shown to support considerable diversity in resistance (Laine et al., 2011; Salvaudon et al., 2008), and theory predicts that this variation is maintained by pathogen-imposed selection. However, empirical support for the role of selection in generating resistance diversity is to date still scarce. With recent advances uncovering the molecular underpinnings of resistance, it is becoming increasingly feasible to study resistance also in non-model systems.

Here, we established a high-quality de novo transcriptome assembly of $P$. lanceolata to investigate the gene expression and processes activated in different plant genotypes in response to inoculation of the same pathogen strain. In our study, all five plant genotypes showed unique gene expression patterns. This was clearly demonstrated in the principal component analysis where the genotypes separate, while the inoculated and mock-inoculated replicates of the same genotype cluster together. Significant variation in gene expression patterns among plant genotypes has also been discovered in other studies (Burghardt et al., 2017; Muller, Kersten, Fladung, \& Schroeder, 2019). In the redundancy analysis (RDA), inoculation explains only 4 $\%$ of the total variation, while genotype-by-inoculation interactions contributes $46 \%$, suggesting that the genotypes have highly unique responses to pathogen attack. While such genotype specificity may be expected between susceptible and resistant genotypes, the split to resistant versus susceptible phenotypes explains only $9 \%$ of the variance, with considerable transcript expression pattern differences between phenotypes. Overall, the plant genotypes also differ by the number, fold change and the function of the transcripts which are differentially expressed in response to the pathogen. Furthermore, even though the gene expression shows the known induction of JA, SA and ABA signaling pathways, they show highly varying activation patterns with JA and ABA significantly contributing to the genotype by experiment differences in RDA. This suggests that different plant genotypes use different strategies in response to the same pathogen, which could be an important mechanism generating phenotypic resistance diversity. One possible explanation for the diverse responses is the extremely high genetic variation within the species; overall, the transcriptome had very high Watterson $\vartheta=0.068$ and nucleotide diversity $\pi=0.077$, suggesting effective population sizes in the order of millions. The high genetic diversity where, on average, eight nucleotides out of 100 differ between any two individuals, is likely manifested also in the diverse responses. The experimental take home message of 
genotype-specific expression pathways to treatment is that including multiple genotypes in experiments and avoiding pooling for RNA-Seq is essential to uncover variation relevant for phenotypic differentiation.

The pathways induced by the pathogen were also visible in the gene expression data. The common responses included the induction of specific nitrate transport genes in susceptible phenotypes as well as elevated expression of photosynthesis-associated genes and related biological processes taking part in chloroplast in all genotypes. The powdery mildew fungi have a contracted carbohydrate metabolism, for example they are not able to degrade pectin, an essential component of plant cell walls (Liang et al., 2018), whereas the lipid metabolism is intact, suggesting that their main source of energy is from lipids. Chlorosis is another hallmark sign of a successful pathogen attack. In our results, the fact that specific nitrate transporters show elevated expression levels as well as chloroplast processes in general, suggests elevated chlorophyll biosynthesis. Together, this suggests that, at least at the early stage of infection, P. plantaginis may target the chloroplast lipids of Plantago to obtain its nutrients, most likely the lipids involved in chlorophyll.

NLRs play an important role in pathogen recognition and downstream defense responses, defense signaling, as well as activation of a hyper sensitive response (Monteiro \& Nishimura, 2018). In our study, we discovered 543 NLR isoforms from a transcriptome that is a combination of the five different Plantago genotype NLR repertoires. Majority of these transcripts were expressed at least at some level in all five plant genotypes. Presence-absence polymorphism in a subset of NLRs has been demonstrated across Arabidopsis accessions (Van de Weyer et al., 2019), and hence it could contribute to the slight differences in the numbers of NLRs detected in the genotypes. Overall, the putative number of NLR genes in P. lanceolata, based on the identified 543 NLR isoforms, seems to be quite high compared to the range reported in other species (Baggs et al., 2017). The high count could result from preferential retention of NLR genes after Plantaginaceae specific whole genome duplication event 46-49 million years ago (Li, Zhang, et al., 2019), since it has been proposed that numerous and highly diversified defense genes are particularly favored in long-lived plants to avoid infection by their rapidly evolving pathogens (Plomion et al., 2018).

The predicted NLR transcripts resulted in 58 clusters of varying sizes, with 22 transcripts in the largest cluster. We also found considerable variation in the branch lengths among clusters, which could indicate variation among clusters in their likelihood to accumulate mutations (Tucker, Ackerman, Eads, Xu, \& Lynch, 2013). Indeed, NLR genes are among the fastest evolving gene families in plants. They often form tandemly arrayed gene clusters, and this is believed to be critical for the fast pace of their structural and functional diversification (Meyers, 2003; Michelmore \& Meyers, 1998). Frequent homologous recombination events and errors produced during the process, followed by diversifying selection, may generate the structural diversity needed to match high effector evolution rates characteristics of the microbes they encounter (Jacob, Vernaldi, \& Maekawa, 2013; McDowell \& Simon, 2006). NLR genes are also under evolutionary pressure resulting from inappropriate activation of cell death. If the plant cannot control NLR-activated cell death, it leads to decreased fitness (Phadnis \& Malik, 2014). In particular, we found an increase in the number of homologs of Arabidopsis RPP13 gene, which is involved in defense against downy mildew (Peronospora parasitica) in Arabidopsis, as well as other defense processes and signaling (Bittner-Eddy, Crute, Holub, \& Beynon, 2000; Rentel, Leonelli, Dahlbeck, Zhao, \& Staskawicz, 2008). While none of the clusters had significant dN/dS values, we found between one and twelve loci under selective pressure in 23 of the clusters. The cluster with the highest number of loci under selection has been suggested to be involved in defense against viruses in Arabidopsis (Revers et al., 2003). The H statistic analysis confirms the transcripts identified by the dN/dS analysis (10 transcripts), as well as identifies 13 other NLR transcripts that may have been under putative selection pressure, two of which show selection in the LRR domain responsible for detecting the type of pathogen.

We find that the NLR transcripts are differentially expressed in response to the pathogen treatment, and that this response varies according to genotype. Transcripts of many NLR genes are known to accumulate in response to defense induction or related stimuli (Lai \& Eulgem, 2018). For example, 75 of the 124 studied Arabidopsis NLR genes were found to exhibit at least two-fold higher transcript levels in response to one or more of the 15 implemented defence-related treatments (Mohr et al., 2010). Up-regulation of NLR 
transcripts after defence induction has also been observed in other plant species, such asBrassica rapa, soybean and rice (Brechenmacher et al., 2015; Chen, Pang, Chen, Zhang, \& Piao, 2015; Ribot et al., 2008). While we were more likely to observe up-regulation of NLR expression levels in response to the pathogen treatment, this was not consistent across transcripts and genotypes. This is in line with recent studies on crop plants testing different genotypes in response to pathogen infection (Cruz-Miralles, Cabedo-Lopez, Perez-Hedo, Flors, \& Jaques, 2019; Sari et al., 2018; Sari, Bhadauria, Vandenberg, \& Banniza, 2017). Plants have evolved mechanisms to stabilize their basal expression levels, and to reduce the fitness costs of an overexpressed immune response that could have more deleterious effects on plant fitness than the infection (Fei, Xia, \& Meyers, 2013). This may explain the down-regulation of some of the NLR transcripts we observe in both susceptible and resistant phenotypes.

Our results here are well in line with the extensive phenotypic variation, and highly strain-specific disease resistance measured in P. lanceolata in earlier studies (Hockerstedt et al., 2018; Jousimo et al., 2014a). High levels of variation in resistance seems to be nearly ubiquitous across natural host populations that experience pathogen-imposed selection without any human interference, in contrast to agricultural systems (Laine et al., 2011; Salvaudon et al., 2008). We show that phenotypic resistance may be generated by different mechanisms. First, we discovered a large repertoire of candidate NLRs inP. lanceolata. We also find evidence of selection generating diversity in a subset of the identified NLRs. Moreover, we discovered that the genotypes have unique expression profiles in response to pathogens, a mechanism which may further contribute to phenotypic variation. Indeed, this high level of genetic and expression profile diversity may be the key to successful defense against pathogens in sessile plants that lack a long lasting immune memory (Hall et al., 2009; Roux \& Bergelson, 2016). Finding different mechanisms that contribute to phenotypic resistance is nontrivial, given how effectively this variation may be utilized to predict and control disease epidemics (Mundt, 2002a). Moreover, resistance in agricultural crops is highly prone to breakdown following pathogen adaptation, and for many commercially important pathogens, the known effective resistance genes are becoming limited. Wild plant populations are currently identified as the most promising source of genes required for development of sustainable agriculture (Fu et al., 2019). In conclusion, characterizing the architecture of resistance in natural host populations may yield unprecedented light on the potential of evolution to generate variation, and it can have broad and long-lasting impacts in our food production environments.

\section{ACKNOWLEDGEMENTS}

We would like to acknowledge Krista Raveala for maintaining the plant and fungal material needed for the experiment. This work was funded by grants from the Academy of Finland (296686) and the European Research Council (Consolidator Grant RESISTANCE 724508) to A-LL, and Academy of Finland (318288) to JS. The authors also wish to acknowledge CSC - IT Center for Science, Finland, for computational resources.

\section{REFERENCES}

1. Adler, D., Nenadic, O., \& Zucchini, W. (2017). RGL: A R-library for 3D visualization with OpenGL.

2. Andolfo, G., Di Donato, A., Chiaiese, P., De Natale, A., Pollio, A., Jones, J. D. G., . . . Ercolano, M. R. (2019). Alien Domains Shaped the Modular Structure of Plant NLR Proteins. Genome Biology and Evolution, 11 (12), 3466-3477. doi:10.1093/gbe/evz248

3. Baggs, E., Dagdas, G., \& Krasileva, K. V. (2017). NLR diversity, helpers and integrated domains: making sense of the NLR IDentity.Current Opinion in Plant Biology, 38 , 59-67. doi:10.1016/j.pbi.2017.04.012

4. Berardini, T. Z., Reiser, L., Li, D., Mezheritsky, Y., Muller, R., Strait, E., \& Huala, E. (2015). The Arabidopsis information resource: Making and mining the "gold standard" annotated reference plant genome. Genesis, 53 (8), 474-485. doi:10.1002/dvg.22877 
5. Bergelson, J., Kreitman, M., Stahl, E. A., \& Tian, D. (2001). Evolutionary Dynamics of Plant Genes. Science, 292 (5525), 2281-2285. doi:10.1126/science.1061337 \%J Science

6. Bever, J. D., Mangan, S. A., \& Alexander, H. M. (2015). Maintenance of Plant Species Diversity by Pathogens. Annual Review of Ecology, Evolution, and Systematics, 46 (1), 305-325. doi:10.1146/annurev-ecolsys-112414-054306

7. Bittner-Eddy, P. D., Crute, I. R., Holub, E. B., \& Beynon, J. L. (2000). RPP13 is a simple locus in Arabidopsis thaliana for alleles that specify downy mildew resistance to different avirulence determinants in Peronospora parasitica. The Plant Journal, 21 (2), 177-188. doi:10.1046/j.1365-313x.2000.00664.x

8. Bolger, A. M., Lohse, M., \& Usadel, B. (2014). Trimmomatic: a flexible trimmer for Illumina sequence data. Bioinformatics, 30 (15), 2114-2120. doi:10.1093/bioinformatics/btu170

9. Borrelli, G. M., Mazzucotelli, E., Marone, D., Crosatti, C., Michelotti, V., Valè, G., \& Mastrangelo, A. M. (2018). Regulation and Evolution of NLR Genes: A Close Interconnection for Plant Immunity.International Journal of Molecular Sciences, 19 (6). doi:10.3390/ijms19061662

10. Bray, N. L., Pimentel, H., Melsted, P., \& Pachter, L. (2016). Near-optimal probabilistic RNA-seq quantification. Nature Biotechnology, 34 (5), 525-527. doi:10.1038/nbt.3519

11. Brechenmacher, L., Nguyen, T. H., Zhang, N., Jun, T. H., Xu, D., Mian, M. A., \& Stacey, G. (2015). Identification of Soybean Proteins and Genes Differentially Regulated in Near Isogenic Lines Differing in Resistance to Aphid Infestation. Journal of Proteome Research, 14 (10), 4137-4146. doi:10.1021/acs.jproteome.5b00146

12. Burghardt, L. T., Guhlin, J., Chun, C. L., Liu, J., Sadowsky, M. J., Stupar, R. M., . . . Tiffin, P. (2017). Transcriptomic basis of genome by genome variation in a legume-rhizobia mutualism. Molecular Ecology, 26 (21), 6122-6135. doi:10.1111/mec.14285

13. Bushnell, W. R. (2002). The role of powdery mildew research in understanding host-parasite interaction: past, present and future.In The Powdery Mildews, A Comprehensive Treatise (Belanger, R. R., Bushnell, W. R., Dik, A. J., and Carver, T. A. W., eds). APS Press, St. Paul, Minnesota, USA., $1-12$.

14. Camacho, C., Coulouris, G., Avagyan, V., Ma, N., Papadopoulos, J., Bealer, K., \& Madden, T. L. (2009). BLAST+: architecture and applications. BMC Bioinformatics, 10 , 421. doi:10.1186/1471$2105-10-421$

15. Chandran, D., Inada, N., Hather, G., Kleindt, C. K., \& Wildermuth, M. C. (2010). Laser microdissection of Arabidopsis cells at the powdery mildew infection site reveals site-specific processes and regulators.Proceedings of the National Academy of Sciences of the United States of America, 107 (1), 460-465. doi:10.1073/pnas.0912492107

16. Chang, S., Puryear, J., \& Cairney, J. (1993). A simple and efficient method for isolating RNA from pine trees. Plant Molecular Biology Reporter, 11 (2), 113-116.

17. Chen, J., Pang, W., Chen, B., Zhang, C., \& Piao, Z. (2015). Transcriptome Analysis of Brassica rapa Near-Isogenic Lines Carrying Clubroot-Resistant and -Susceptible Alleles in Response to Plasmodiophora brassicae during Early Infection. Frontiers in Plant Science, 6 , 1183. doi:10.3389/fpls.2015.01183

18. Chisholm, S. T., Coaker, G., Day, B., \& Staskawicz, B. J. (2006). Host-microbe interactions: shaping the evolution of the plant immune response. Cell, 124 (4), 803-814. doi:10.1016/j.cell.2006.02.008

19. Choi, J., Choi, D., Lee, S., Ryu, C. M., \& Hwang, I. (2011). Cytokinins and plant immunity: old foes or new friends? Trends in Plant Science, 16 (7), 388-394. doi:10.1016/j.tplants.2011.03.003

20. Coll, N. S., Epple, P., \& Dangl, J. L. (2011). Programmed cell death in the plant immune system. Cell Death 85 Differentiation, 18 (8), 1247-1256. doi:10.1038/cdd.2011.37

21. Cruz-Miralles, J., Cabedo-Lopez, M., Perez-Hedo, M., Flors, V., \& Jaques, J. A. (2019). Zoophytophagous mites can trigger plant-genotype specific defensive responses affecting potential prey beyond predation: the case of Euseius stipulatus and Tetranychus urticae in citrus. Pest Managment Science, 75 (7), 1962-1970. doi:10.1002/ps.5309

22. Davidson, N. M., Hawkins, A. D. K., \& Oshlack, A. (2017). SuperTranscripts: a data driven reference for analysis and visualisation of transcriptomes. Genome Biology, 18 (1), 148. doi:10.1186/s13059- 
017-1284-1

23. Decaestecker, E., Gaba, S., Raeymaekers, J. A., Stoks, R., Van Kerckhoven, L., Ebert, D., \& De Meester, L. (2007). Host-parasite 'Red Queen' dynamics archived in pond sediment. Nature, 450 (7171), 870-873. doi:10.1038/nature06291

24. Dusa, A. (2018). venn: Draw Venn Diagrams. $R$ package, version 1.7.

25. Egorov, T. A., \& Odintsova, T. I. (2012). Defense peptides of plant immunity. Russian Journal of Bioorganic Chemistry, 38 (1), 1-9. doi:10.1134/s1068162012010062

26. Fay, J. C., \& Wu, C. I. (2000). Hitchhiking under positive Darwinian selection. Genetics, 155 (3), 1405-1413.

27. Fei, Q., Xia, R., \& Meyers, B. C. (2013). Phased, Secondary, Small Interfering RNAs in Posttranscriptional Regulatory Networks. The Plant Cell, 25 (7), 2400-2415. doi:10.1105/tpc.113.114652

28. Fu, Y. B., Peterson, G. W., Horbach, C., Konkin, D. J., Beiles, A., \& Nevo, E. (2019). Elevated mutation and selection in wild emmer wheat in response to 28 years of global warming. Proceedings of the National Academy of Sciences (PNAS) USA, 116 (40), 20002-20008. doi:10.1073/pnas.1909564116

29. Gilbert, D. (2013). Gene-omes built from mRNA seq not genome DNA. 7th annual arthropod genomics symposium. Notre Dame.

30. Gilligan, C. A. (2002). An epidemiological framework for disease management. In Advances in Botanical Research (Vol. 38, pp. 1-64): Academic Press.

31. Gohre, V. (2015). Immune responses: Photosynthetic defence.Nature Plants, 1 , 15079. doi:10.1038/nplants.2015.79

32. Gomez, P., \& Buckling, A. (2011). Bacteria-Phage Antagonistic Coevolution in Soil. Science, 332 (6025), 106-109. doi:10.1126/science.1198767 \%J Science

33. Grabherr, M. G., Haas, B. J., Yassour, M., Levin, J. Z., Thompson, D. A., Amit, I., . . . Regev, A. (2011). Full-length transcriptome assembly from RNA-Seq data without a reference genome. Nature Biotechnology, 29 (7), 644-652. doi:10.1038/nbt.1883

34. Greischar, M. A., \& Koskella, B. (2007). A synthesis of experimental work on parasite local adaptation. Ecology Letters, 10 (5), 418-434. doi:10.1111/j.1461-0248.2007.01028.x

35. Hahlbrock, K., Scheel, D., Logemann, E., Nurnberger, T., Parniske, M., Reinold, S., . . . Schmelzer, E. (1995). Oligopeptide elicitor-mediated defense gene activation in cultured parsley cells.Proceedings of the National Academy of Sciences of the United States of America, 92 (10), 41504157. doi:10.1073/pnas.92.10.4150

36. Hall, S. A., Allen, R. L., Baumber, R. E., Baxter, L. A., Fisher, K., Bittner-Eddy, P. D., . . . Beynon, J. L. (2009). Maintenance of genetic variation in plants and pathogens involves complex networks of gene-for-gene interactions. Molecular Plant Pathology, 10 (4), 449-457. doi:10.1111/j.13643703.2009.00544.x

37. Hamilton, W. D. (1980). Sex versus Non-Sex versus Parasite.Oikos, 35 (2), $282-290$. doi: $10.2307 / 3544435$

38. Hockerstedt, L. M., Siren, J. P., \& Laine, A. L. (2018). Effect of spatial connectivity on host resistance in a highly fragmented natural pathosystem. Journal of Evolutionary Biology, 31 (6), $844-852$. doi:10.1111/jeb.13268

39. Hoeksema, J. D., \& Forde, S. E. (2008). A meta-analysis of factors affecting local adaptation between interacting species. The American Naturalist, 171 (3), 275-290. doi:10.1086/527496

40. Hua, L. (2009). Dissection of salicylic acid-mediated defense signaling networks. Plant Signaling and Behavior, 4 (8), 713-717. doi:10.4161/psb.4.8.9173

41. Jacob, F., Vernaldi, S., \& Maekawa, T. (2013). Evolution and Conservation of Plant NLR Functions. Frontiers in Immunology, 4 , 297. doi:10.3389/fimmu.2013.00297

42. Jaenike, J. (1978). Host Selection by Mycophagous Drosophila.ECOLOGY, 59 (6), $1286-1288$. doi: $10.2307 / 1938245$

43. Jensen, M. K., Hagedorn, P. H., de Torres-Zabala, M., Grant, M. R., Rung, J. H., Collinge, D. B., \& Lyngkjaer, M. F. (2008). Transcriptional regulation by an NAC (NAM-ATAF1,2-CUC2) transcription factor attenuates ABA signalling for efficient basal defence towards Blumeria graminis f. sp. hordei in 
Arabidopsis. The Plant Journal, 56 (6), 867-880. doi:10.1111/j.1365-313X.2008.03646.x

44. Jones, J. D., \& Dangl, J. L. (2006). The plant immune system.Nature, 444 (7117), 323-329. doi:10.1038/nature05286

45. Jones, P., Binns, D., Chang, H. Y., Fraser, M., Li, W., McAnulla, C., . . . Hunter, S. (2014). InterProScan 5: genome-scale protein function classification. Bioinformatics, 30 (9), 1236-1240. doi:10.1093/bioinformatics/btu031

46. Jousimo, Tack, A. J., Ovaskainen, O., Mononen, T., Susi, H., Tollenaere, C., \& Laine, A. L. (2014a). Ecological and evolutionary effects of fragmentation on infectious disease dynamics.Science, 344 (6189), 1289-1293. doi:10.1126/science.1253621

47. Jousimo, J., Tack, A. J. M., Ovaskainen, O., Mononen, T., Susi, H., Tollenaere, C., \& Laine, A.L. (2014b). Ecological and evolutionary effects of fragmentation on infectious disease dynamics.344 (6189), 1289-1293. doi:10.1126/science.1253621 \%J Science

48. Kachroo, A., \& Kachroo, P. (2009). Fatty Acid-derived signals in plant defense. Annual Review of Phytopathology, 47 , 153-176. doi:10.1146/annurev-phyto-080508-081820

49. Karim, S., Holmstrom, K. O., Mandal, A., Dahl, P., Hohmann, S., Brader, G., . . . Pirhonen, M. (2007). AtPTR3, a wound-induced peptide transporter needed for defence against virulent bacterial pathogens in Arabidopsis. Planta, 225 (6), 1431-1445. doi:10.1007/s00425-006-0451-5

50. Klopfenstein, D. V., Zhang, L., Pedersen, B. S., Ramirez, F., Warwick Vesztrocy, A., Naldi, A., . . . Tang, H. (2018). GOATOOLS: A Python library for Gene Ontology analyses. Scientific Reports, 8 (1), 10872. doi:10.1038/s41598-018-28948-z

51. Koff, R. S. (1992). Infectious diseases of humans: Dynamics and control. By R.M. Anderson and R.M. May, 757 pp. Oxford: Oxford University Press, 1991. \$95.00. Hepatology, 15 (1), 169-169. doi:10.1002/hep.1840150131

52. Korneliussen, T. S., Albrechtsen, A., \& Nielsen, R. (2014). ANGSD: Analysis of Next Generation Sequencing Data. BMC Bioinformatics, 15 (1), 356. doi:10.1186/s12859-014-0356-4

53. Kryazhimskiy, S., \& Plotkin, J. B. (2008). The population genetics of dN/dS. PLoS Genetics, 4 (12), e1000304. doi:10.1371/journal.pgen.1000304

54. Kuniak, E., \& Urbanek, H. (2000). The involvement of hydrogen peroxide in plant responses to stresses. Acta Physiologiae Plantarum, 22 (2), 95-203. doi:https://doi.org/10.1007/s11738-000-0076-4

55. Kursar, T. A., Dexter, K. G., Lokvam, J., Pennington, R. T., Richardson, J. E., Weber, M. G., . - . Coley, P. D. (2009). The evolution of antiherbivore defenses and their contribution to species coexistence in the tropical tree genus \&lt;em\&gt;Inga\&lt;/em\&gt.Proceedings of the National Academy of Sciences, 106 (43), 18073. doi:10.1073/pnas.0904786106

56. Lai, Y., \& Eulgem, T. (2018). Transcript-level expression control of plant NLR genes. Molecular Plant Pathology, 19 (5), 1267-1281. doi:10.1111/mpp.12607

57. Laine, A. L. (2004). Resistance variation within and among host populations in a plant-pathogen metapopulation: implications for regional pathogen dynamics. Journal of Ecology, 92 (6), 990-1000. doi:doi:10.1111/j.0022-0477.2004.00925.x

58. Laine, A. L. (2005). Spatial scale of local adaptation in a plant-pathogen metapopulation. Journal of Evolutionary Biology, 18 (4), 930-938. doi:10.1111/j.1420-9101.2005.00933.x

59. Laine, A. L. (2006). Evolution of host resistance: looking for coevolutionary hotspots at small spatial scales. Proceedings of the Royal Society B: Biological Sciences, 273 (1584), 267-273. doi:10.1098/rspb.2005.3303

60. Laine, A. L. (2007). Pathogen fitness components and genotypes differ in their sensitivity to nutrient and temperature variation in a wild plant-pathogen association. Journal of Evolutionary Biology, 20 (6), 2371-2378. doi:10.1111/j.1420-9101.2007.01406.x

61. Laine, A. L. (2008). Temperature-mediated patterns of local adaptation in a natural plant-pathogen metapopulation. Ecology Letters, 11 (4), 327-337. doi:10.1111/j.1461-0248.2007.01146.x

62. Laine, A. L., Burdon, J. J., Dodds, P. N., \& Thrall, P. H. (2011). Spatial variation in disease resistance: from molecules to metapopulations. Journal of Ecology, 99 (1), 96-112. doi:10.1111/j.13652745.2010.01738.x 
63. Le Roy, J., Huss, B., Creach, A., Hawkins, S., \& Neutelings, G. (2016). Glycosylation Is a Major Regulator of Phenylpropanoid Availability and Biological Activity in Plants. Frontiers in Plant Science, 7 , 735. doi:10.3389/fpls.2016.00735

64. Leonard, K. J. (1977). Selection pressure and plant pathogens.Annals of the New York Academy of Sciences, 287 (1), 207-222. doi:10.1111/j.1749-6632.1977.tb34240.x

65. Li, B., Ruotti, V., Stewart, R. M., Thomson, J. A., \& Dewey, C. N. (2010). RNA-Seq gene expression estimation with read mapping uncertainty. Bioinformatics, 26 (4), 493-500. doi:10.1093/bioinformatics/btp692

66. Li, G., Xu, X., Bai, G., Carver, B. F., Hunger, R., \& Bonman, J. M. (2016). Identification of Novel Powdery Mildew Resistance Sources in Wheat. Acess DL, 56 (4), 1817-1830. doi:10.2135/cropsci2015.09.0551

67. Li, H., Dong, Z., Ma, C., Tian, X., Xiang, Z., Xia, Q., . . . Liu, W. (2019). Discovery of powdery mildew resistance gene candidates from Aegilops biuncialis chromosome $2 \mathrm{Mb}$ based on transcriptome sequencing.PLoS One, 14 (11), e0220089. doi:10.1371/journal.pone.0220089

68. Li, M., Zhang, D., Gao, Q., Luo, Y., Zhang, H., Ma, B., . . . Xue, Y. (2019). Genome structure and evolution of Antirrhinum majus L.Nature Plants, 5 (2), 174-183. doi:10.1038/s41477-018-0349-9

69. Liang, P., Liu, S., Xu, F., Jiang, S., Yan, J., He, Q., . . . Miao, W. (2018). Powdery Mildews Are Characterized by Contracted Carbohydrate Metabolism and Diverse Effectors to Adapt to Obligate Biotrophic Lifestyle. Frontiers in Microbiology, 9 , 3160. doi:10.3389/fmicb.2018.03160

70. Love, M. I., Huber, W., \& Anders, S. (2014). Moderated estimation of fold change and dispersion for RNA-seq data with DESeq2. Genome Biology, 15 (12), 550. doi:10.1186/s13059-014-0550-8

71. McDowell, J. M., \& Simon, S. A. (2006). Recent insights into R gene evolution. Molecular Plant Pathology, 7 (5), 437-448. doi:10.1111/j.1364-3703.2006.00342.x

72. Meunier, E., \& Broz, P. (2017). Evolutionary Convergence and Divergence in NLR Function and Structure. Trends in Immunology, 38 (10), 744-757. doi:10.1016/j.it.2017.04.005

73. Meyers, B. C. (2003). Genome-Wide Analysis of NBS-LRR-Encoding Genes in Arabidopsis. The Plant Cell Online, 15 (4), 809-834. doi:10.1105/tpc.009308

74. Michelmore, R. W., \& Meyers, B. C. (1998). Clusters of Resistance Genes in Plants Evolve by Divergent Selection and a Birth-and-Death Process. GENOME RESEARCH (8), 1113-1130. doi:10.1101/gr.8.11.1113

75. Miedes, E., Vanholme, R., Boerjan, W., \& Molina, A. (2014). The role of the secondary cell wall in plant resistance to pathogens.Frontiers in Plant Science, 5 , 358. doi:10.3389/fpls.2014.00358

76. Mitchell, A. L., Attwood, T. K., Babbitt, P. C., Blum, M., Bork, P., Bridge, A., . . . Finn, R. D. (2019). InterPro in 2019: improving coverage, classification and access to protein sequence annotations. Nucleic Acids Research, 47 (D1), D351-D360. doi:10.1093/nar/gky1100

77. Mock, H. P., Keetman, U., Kruse, E., Rank, B., \& Grimm, B. (1998). Defense Responses to Tetrapyrrole-Induced Oxidative Stress in Transgenic Plants with Reduced Uroporphyrinogen Decarboxylase or Coproporphyrinogen Oxidase Activity. Plant Physiology, 116 (1), 107. doi:10.1104/pp.116.1.107

78. Mohr, T. J., Mammarella, N. D., Hoff, T., Woffenden, B. J., Jelesko, J. G., \& McDowell, J. M. (2010). The Arabidopsis Downy Mildew Resistance Gene RPP8 Is Induced by Pathogens and Salicylic Acid and Is Regulated by W Box cis Elements. Molecular Plant-Microbe Interactions(r), 23 (10), 1303-1315. doi:10.1094/MPMI-01-10-0022

79. Monteiro, F., \& Nishimura, M. T. (2018). Structural, Functional, and Genomic Diversity of Plant NLR Proteins: An Evolved Resource for Rational Engineering of Plant Immunity. Annual Review of Phytopathology, 56 , 243-267. doi:10.1146/annurev-phyto-080417-045817

80. Muller, N. A., Kersten, B., Fladung, M., \& Schroeder, H. (2019). RNA-seq of eight different poplar clones reveals conserved up-regulation of gene expression in response to insect herbivory. $B M C G e-$ nomics, 20 (1), 673. doi:10.1186/s12864-019-6048-8

81. Mundt, C. C. (2002a). Use of multiline cultivars and cultivar mixtures fo disease management. Annual Review of Phytopathology, 40 (1), 381-410. doi:10.1146/annurev.phyto.40.011402.113723 
82. Mundt, C. C. (2002b). Use of multiline cultivars and cultivar mixtures for disease management. 40 (1), 381-410. doi:10.1146/annurev.phyto.40.011402.113723

83. Mundt, C. C. (2014). Durable resistance: a key to sustainable management of pathogens and pests. Infection, Genetics and Evolution, 27, 446-455. doi:10.1016/j.meegid.2014.01.011

84. Mur, L. A. J., Simpson, C., Kumari, A., Gupta, A. K., \& Gupta, K. J. (2017). Moving nitrogen to the centre of plant defence against pathogens. Annals of Botany, 119 (5), 703-709. doi:10.1093/aob/mcw179

85. Niu, L., \& Liao, W. (2016). Hydrogen Peroxide Signaling in Plant Development and Abiotic Responses: Crosstalk with Nitric Oxide and Calcium. Frontiers in Plant Science, 7 , 230. doi:10.3389/fpls.2016.00230

86. Nurnberger, T., Nennstiel, D., Jabs, T., Sacks, W. R., Hahlbrock, K., \& Scheel, D. (1994). High affinity binding of a fungal oligopeptide elicitor to parsley plasma membranes triggers multiple defense responses. Cell, 78 (3), 449-460. doi:https://doi.org/10.1016/0092-8674(94)90423-5

87. Oksanen, J., Blanchet, F. G., Friendly, M., Kindt, R., Legendre, P., McGlinn, D., . . . Wagner, H. (2018). vegan: Community Ecology Package. $R$ package, version 2.5-3.

88. Perez-Bueno, M. L., Pineda, M., \& Baron, M. (2019). Phenotyping Plant Responses to Biotic Stress by Chlorophyll Fluorescence Imaging. Frontiers in Plant Science, 10 , 1135. doi:10.3389/fpls.2019.01135

89. Phadnis, N., \& Malik, H. S. (2014). Speciation via autoimmunity: a dangerous mix. Cell, 159 (6), 1247-1249. doi:10.1016/j.cell.2014.11.028

90. Pike, S., Gao, F., Kim, M. J., Kim, S. H., Schachtman, D. P., \& Gassmann, W. (2014). Members of the NPF3 transporter subfamily encode pathogen-inducible nitrate/nitrite transporters in grapevine and Arabidopsis. Plant and Cell Physiology, 55 (1), 162-170. doi:10.1093/pcp/pct167

91. Plomion, C., Aury, J. M., Amselem, J., Leroy, T., Murat, F., Duplessis, S., . . . Salse, J. (2018). Oak genome reveals facets of long lifespan. Nature Plants, 4 (7), 440-452. doi:10.1038/s41477-018-0172-3

92. Polonio, A., Pineda, M., Bautista, R., Martinez-Cruz, J., Perez-Bueno, M. L., Baron, M., \& PerezGarcia, A. (2019). RNA-seq analysis and fluorescence imaging of melon powdery mildew disease reveal an orchestrated reprogramming of host physiology. Scientific Reports, 9 (1). doi:10.1038/s41598-01944443-5

93. Price, M. N., Dehal, P. S., \& Arkin, A. P. (2010). FastTree 2-approximately maximum-likelihood trees for large alignments.PLoS One, 5 (3), e9490. doi:10.1371/journal.pone.0009490

94. Pruitt, K. D., Tatusova, T., \& Maglott, D. R. (2007). NCBI reference sequences (RefSeq): a curated non-redundant sequence database of genomes, transcripts and proteins. Nucleic Acids Research, 35 (Database issue), D61-65. doi:10.1093/nar/gkl842

95. Ragonnet-Cronin, M., Hodcroft, E., Hue, S., Fearnhill, E., Delpech, V., Leigh Brown, A. J., \& Lycett, S. (2013). Automated analysis of phylogenetic clusters. BMC Bioinformatics, 14 (317). doi:10.1186/1471-2105-14-317

96. Rentel, M. C., Leonelli, L., Dahlbeck, D., Zhao, B., \& Staskawicz, B. J. (2008). Recognition of the Hyaloperonospora parasitica effector ATR13 triggers resistance against oomycete, bacterial, and viral pathogens. Proceedings of the National Academy of Sciences of the United States of America, 105 (3), 1091-1096. doi:10.1073/pnas.0711215105

97. Revers, F., Guiraud, T., Houvenaghel, M. C., Mauduit, T., Le Gall, O., \& Candresse, T. (2003). Multiple Resistance Phenotypes to Lettuce mosaic virus Among Arabidopsis thaliana Accessions. Molecular Plant-Microbe Interactions, 16 (7), 608-616. doi:10.1094/MPMI.2003.16.7.608

98. Ribot, C., Hirsch, J., Balzergue, S., Tharreau, D., Notteghem, J. L., Lebrun, M. H., \& Morel, J. B. (2008). Susceptibility of rice to the blast fungus, Magnaporthe grisea. Journal of Plant Physiology, 165 (1), 114-124. doi:10.1016/j.jplph.2007.06.013

99. Rose, L. E., Bittner-Eddy, P. D., Langley, C. H., Holub, E. B., Michelmore, R. W., \& Beynon, J. L. (2004). The Maintenance of Extreme Amino Acid Diversity at the Disease Resistance Gene, $<\mathrm{em}>\mathrm{RPP} 13</ \mathrm{em}>$, in $<\mathrm{em}>$ Arabidopsis thaliana $</ \mathrm{em}>$. Genetics, 166 (3), 1517-1527. doi:10.1534/genetics.166.3.1517 \%J Genetics

100. Roux, F., \& Bergelson, J. (2016). Chapter Four - The Genetics Underlying Natural Variation in the 
Biotic Interactions of Arabidopsis thaliana: The Challenges of Linking Evolutionary Genetics and Community Ecology. In V. Orgogozo (Ed.), Current Topics in Developmental Biology (Vol. 119, pp. 111-156): Academic Press.

101. Rozen, S., \& Skaletsky, H. (1999). Primer3 on the WWW for General Users and for Biologist Programmers. In S. Misener \& S. A. Krawetz (Eds.), Bioinformatics Methods and Protocols (pp. 365-386). Totowa, NJ: Humana Press.

102. Sagar, G. R., \& Harper, J. L. (1964). Plantago Major L., P. Media L. and P. Lanceolata L. Journal of Ecology, 52 (1), 189-221. doi:10.2307/2257792

103. Salvaudon, L., Giraud, T., \& Shykoff, J. A. (2008). Genetic diversity in natural populations: a fundamental component of plant-microbe interactions. Current Opinion in Plant Biology, 11 (2), 135-143. doi:10.1016/j.pbi.2008.02.002

104. Sari, E., Bhadauria, V., Ramsay, L., Borhan, M. H., Lichtenzveig, J., Bett, K. E., . . . Banniza, S. (2018). Defense responses of lentil (Lens culinaris) genotypes carrying non-allelic ascochyta blight resistance genes to Ascochyta lentis infection. PLoS One, 13 (9), e0204124. doi:10.1371/journal.pone.0204124

105. Sari, E., Bhadauria, V., Vandenberg, A., \& Banniza, S. (2017). Genotype-Dependent Interaction of Lentil Lines with Ascochyta lentis.Frontiers in Plant Science, 8 , 764. doi:10.3389/fpls.2017.00764

106. Sarris, P. F., Cevik, V., Dagdas, G., Jones, J. D., \& Krasileva, K. V. (2016). Comparative analysis of plant immune receptor architectures uncovers host proteins likely targeted by pathogens. BMC Biology, 14 , 8. doi:10.1186/s12915-016-0228-7

107. Schulz, M. H., Zerbino, D. R., Vingron, M., \& Birney, E. (2012). Oases: robust de novo RNAseq assembly across the dynamic range of expression levels. Bioinformatics, 28 (8), 1086-1092. doi:10.1093/bioinformatics/bts094

108. Seppey, M., Manni, M., \& Zdobnov, E. M. (2019). BUSCO: Assessing Genome Assembly and Annotation Completeness. In M. Kollmar (Ed.), Gene Prediction: Methods and Protocols (pp. 227-245). New York, NY: Springer New York.

109. Shang, X., Cao, Y., \& Ma, L. (2017). Alternative Splicing in Plant Genes: A Means of Regulating the Environmental Fitness of Plants.International Journal of Molecular Sciences, 18 (2). doi:10.3390/ijms18020432

110. Shao, Z. Q., Xue, J. Y., Wu, P., Zhang, Y. M., Wu, Y., Hang, Y. Y., . . . Chen, J. Q. (2016). Large-Scale Analyses of Angiosperm Nucleotide-Binding Site-Leucine-Rich Repeat Genes Reveal Three Anciently Diverged Classes with Distinct Evolutionary Patterns.Plant Physiology, 170 (4), 2095-2109. doi:10.1104/pp.15.01487

111. Sheshukova, E. V., Komarova, T. V., Pozdyshev, D. V., Ershova, N. M., Shindyapina, A. V., Tashlitsky, V. N., . . . Dorokhov, Y. L. (2017). The Intergenic Interplay between Aldose 1-Epimerase-Like Protein and Pectin Methylesterase in Abiotic and Biotic Stress Control.Frontiers in Plant Science, 8 . doi:10.3389/fpls.2017.01646

112. Soneson, C., Love, M. I., \& Robinson, M. D. (2015). Differential analyses for RNA-seq: transcript-level estimates improve gene-level inferences. F1000Research, 4 , 1521. doi:10.12688/f1000research.7563.2

113. Srivastava, A., Sarkar, H., Malik, L., \& Patro, R. (2016). Accurate, Fast and Lightweight Clustering of de novo Transcriptomes using Fragment Equivalence Classes. eprint arXiv:1604.03250 .

114. Staiger, D., Korneli, C., Lummer, M., \& Navarro, L. (2013). Emerging role for RNA-based regulation in plant immunity. New Phytologist, 197 (2), 394-404. doi:10.1111/nph.12022

115. Stam, R., Silva-Arias, G. A., Nosenko, T., Scheikl, D., Horger, A. C., Stephan, W., . . . Tellier, A. (2017). A small subset of NLR genes drives local adaptation to pathogens in wild tomato. bioRxiv . doi: $10.1101 / 210559$

116. Steuernagel, B., Jupe, F., Witek, K., Jones, J. D., \& Wulff, B. B. (2015). NLR-parser: rapid annotation of plant NLR complements.Bioinformatics, 31 (10), 1665-1667. doi:10.1093/bioinformatics/btv005

117. Thompson, J. N., \& Burdon, J. J. (1992). Gene-for-gene coevolution between plants and parasites. Nature, 360 (6400), 121-125. doi:10.1038/360121a0

118. Thrall, P. H., Laine, A. L., Ravensdale, M., Nemri, A., Dodds, P. N., Barrett, L. G., \& Burdon, 
J. J. (2012). Rapid genetic change underpins antagonistic coevolution in a natural host-pathogen metapopulation. Ecology Letters, 15 (5), 425-435. doi:10.1111/j.1461-0248.2012.01749.x

119. Tucker, A. E., Ackerman, M. S., Eads, B. D., Xu, S., \& Lynch, M. (2013). Population-genomic insights into the evolutionary origin and fate of obligately asexual Daphnia pulex. Proceedings of the National Academy of Sciences, 110 (39), 15740-15745. doi:10.1073/pnas.1313388110

120. Upson, J. L., Zess, E. K., Bialas, A., Wu, C. H., \& Kamoun, S. (2018). The coming of age of EvoMPMI: evolutionary molecular plant-microbe interactions across multiple timescales. Current Opinion in Plant Biology, 44 , 108-116. doi:10.1016/j.pbi.2018.03.003

121. Wallstrom, S. V., Florez-Sarasa, I., Araujo, W. L., Aidemark, M., Fernandez-Fernandez, M., Fernie, A. R., . . . Rasmusson, A. G. (2014). Suppression of the external mitochondrial NADPH dehydrogenase, NDB1, in Arabidopsis thaliana affects central metabolism and vegetative growth. Molecular Plant, 7 (2), 356-368. doi:10.1093/mp/sst115

122. Walters, D. R., \& McRoberts, N. (2006). Plants and biotrophs: a pivotal role for cytokinins? Trends Plant Science, 11 (12), 581-586. doi:10.1016/j.tplants.2006.10.003

123. Van de Weyer, A. L., Monteiro, F., Furzer, O. J., Nishimura, M. T., Cevik, V., Witek, K., . . . Bemm, F. (2019). A Species-Wide Inventory of NLR Genes and Alleles in Arabidopsis thaliana. Cell, 178 (5), 1260-1272.e1214. doi:10.1016/j.cell.2019.07.038

124. Van Ooijen, G., Mayr, G., Kasiem, M. M. A., Albrecht, M., Cornelissen, B. J. C., \& Takken, F. L. W. (2008). Structure-function analysis of the NB-ARC domain of plant disease resistance proteins. Journal of Experimental Botany, 59 (6), 1383-1397. doi:10.1093/jxb/ern045

125. Varemo, L., Nielsen, J., \& Nookaew, I. (2013). Enriching the gene set analysis of genome-wide data by incorporating directionality of gene expression and combining statistical hypotheses and methods.Nucleic Acids Research, 41 (8), 4378-4391. doi:10.1093/nar/gkt111

126. Wickham H. (2016). ggplot2: Elegant Graphics for Data Analysis.Springer-Verlag New York.

127. Wiese, J., Kranz, T., \& Schubert, S. (2004). Induction of pathogen resistance in barley by abiotic stress. Plant Biology, 6 (5), 529-536. doi:10.1055/s-2004-821176

128. Woolhouse, M. E. J., Taylor, L. H., \& Haydon, D. T. (2001). Population Biology of Multihost Pathogens. Science, 292 (5519), 1109-1112. doi:10.1126/science.1059026 \%J Science

129. Xie, Y., Wu, G., Tang, J., Luo, R., Patterson, J., Liu, S., . . . Wang, J. (2014). SOAPdenovoTrans: de novo transcriptome assembly with short RNA-Seq reads. Bioinformatics, 30 (12), 1660-1666. doi:10.1093/bioinformatics/btu077

130. Yang, J., Duan, G., Li, C., Liu, L., Han, G., Zhang, Y., \& Wang, C. (2019). The Crosstalks Between Jasmonic Acid and Other Plant Hormone Signaling Highlight the Involvement of Jasmonic Acid as a Core Component in Plant Response to Biotic and Abiotic Stresses.Frontiers in Plant Science, 10 . doi:10.3389/fpls.2019.01349

131. Yang, Z. (2007). PAML 4: phylogenetic analysis by maximum likelihood.Molecular Biology and Evolution, 24 (8), 1586-1591. doi:10.1093/molbev/msm088

132. Yu, G., Smith, D. K., Zhu, H., Guan, Y., Lam, T. T., \& McInerny, G. (2017). ggtree: anrpackage for visualization and annotation of phylogenetic trees with their covariates and other associated data. Methods in Ecology and Evolution, 8 (1), 28-36. doi:10.1111/2041-210x.12628

133. Zhou, J., Sun, A., \& Xing, D. (2013). Modulation of cellular redox status by thiamine-activated NADPH oxidase confers Arabidopsis resistance to Sclerotinia sclerotiorum. Journal of Experimental Botany, 64 (11), 3261-3272. doi:10.1093/jxb/ert166

134. Zhu, Y., Chen, H., Fan, J., Wang, Y., Li, Y., Chen, J., . . . Mundt, C. C. (2000). Genetic diversity and disease control in rice.Nature, 406 (6797), 718-722. doi:10.1038/35021046

\section{Data Accessibility}

Upon acceptance, all data associated with this study will be deposited into NCBI (SUB6931705). 


\section{Author Contribution}

A-LL, JS, PS and LH conceived the ideas and JS, PS, LH, MB and A-LL designed experiment. LH conducted the experimental work and PS, JS and LH analyzed the data. PS, JS and A-LL led the writing of the manuscript; all the authors contributed to the drafts and gave final approval for publication.

\section{Safdari et al. Tables \& Figures}

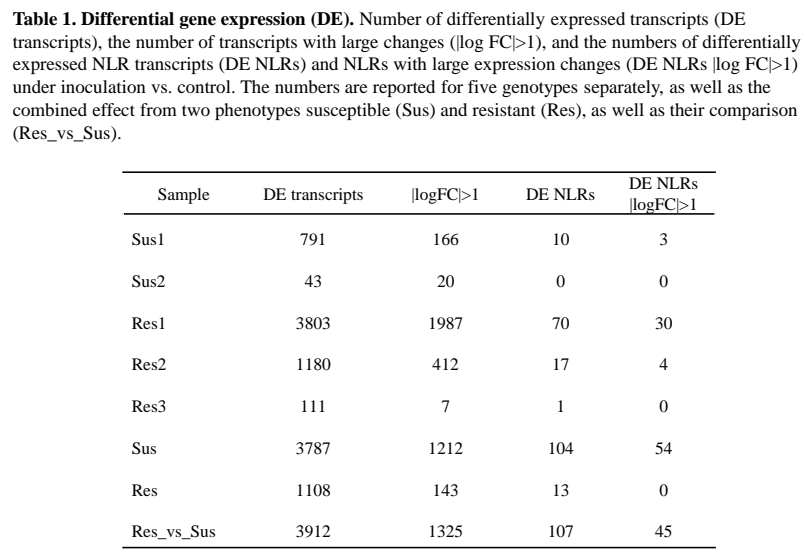

